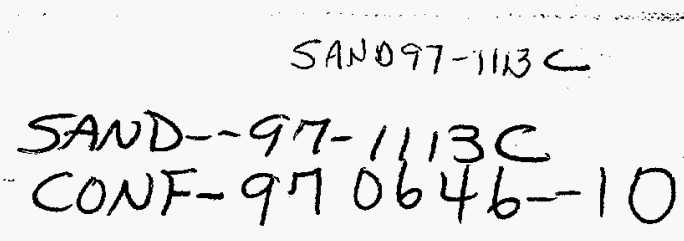

\title{
Optimizing Surface Acoustic Wave Sensors for Trace Chemical Detection
}

\author{
Gregory C. Frye, Richard J. Kottenstette, Edwin J. Heller, C. Jeffrey Brinker, Stephen A. Casalnuovo, Alan \\ Sellinger, Narayan K. Raman, and Yunfeng Lu \\ Sandia National Laboratories, PO Box 5800, MS-1425, Albuquerque, NM 87185, USA, gcfrye@sandia.gov
}

\section{SUMMARY}

This paper describes several recent advances for fabricating coated surface acoustic wave (SAW) sensors for applications requiring trace chemical detection. Specifically, we have demonstrated that high surface area microporous oxides can provide 100 -fold improvements in SAW sensor responses compared with more typical polymeric coatings. In addition, we fabricated GaAs SAW devices with frequencies up to $500 \mathrm{MHz}$ to provide greater sensitivity and an ideal substrate for integration with high-frequency electronics.

Keywords: Surface acoustic wave, SAW, chemical sensor

\section{INTRODUCTION}

As shown in Figure 1, SAW dèvices consist of a piezoelectric substrate, typically quartz, and two interdigitated transducers formed by photolithographic patterning of a thin metal layer. Application of an alternating voltage to the input transducer generates an alternating strain field that launches a surface acoustic wave. This wave travels along the substrate surface before being converted back into an electrical signal by the output transducer. The velocity and attenuation of

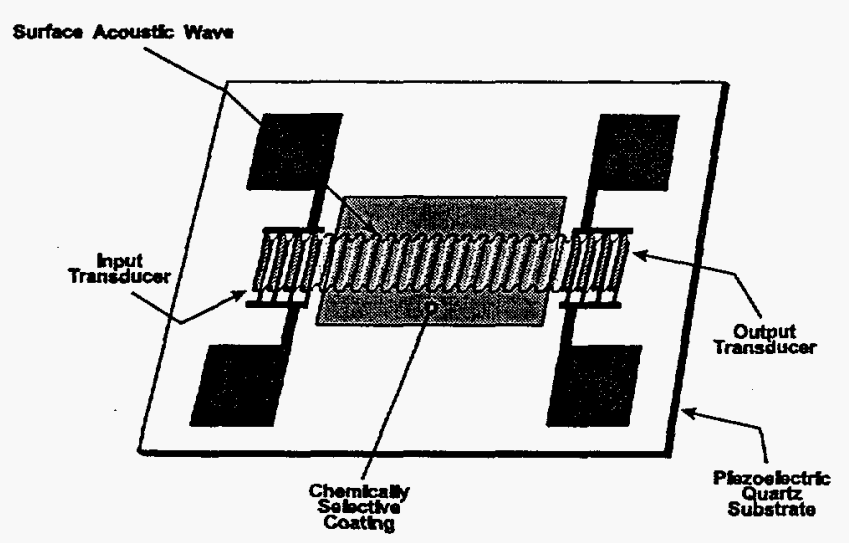

Fig. 1: Schematic of a surface acoustic wave sensor. the propagating wave are very sensitive to properties, such as mass and viscoelasticity, of thin films formed on the device surface. For example, increases in surface mass loading cause decreases in wave velocity that can be used to detect picogram mass changes [1]. By coating the acoustic path with a material that sorbs a chemical analyte of interest, this sensitivity can also be used to develop chemical sensors [1-3]. This paper describes work to enhance the performance of coated SAW sensors for trace chemical detection using specialized coatings and high frequency SAW devices.

\section{SENSOR COATINGS}

Coating materials that provide high analyte uptake (large mass changes) at low chemical concentrations are critical to trace detection with SAW sensors. Our group [2] and others [3] have demonstrated that polymercoated SAWs are useful for detecting a wide range of analytes, including volatile organic compounds (VOCs) [2] and chemical warfare (CW) agents [3]. An example is shown in Figure 2, where VOC challenges are seen to be rapidly and reversibly detected by both quartz and GaAs SAW devices coated with poly(isobutylene) (PIB). Due in part to the fact that molecular interactions between polymer chains are lost when a cavity is formed for analyte absorption, partition coefficients in polymers are not as high as with microporous materials.

Using sol-gel chemistry [4], we have developed techniques for fabricating thin films of microporous oxides on SAW devices. One type of microporous oxide coating solution was made by a variant of a two-step acid-catalyzed (A2 sol-gel) reaction procedure in which a portion of the tetraethoxysilane was substituted with phenyltriethoxysilane [5]. Dip-coating followed by pyrolysis under reducing conditions resulted in a microporous film with average pore diameter $\sim 0.8 \mathrm{~nm}$ and hydrophobic pore surfaces that minimized sensitivity to water vapor, an ever present interferant. Results presented in Figure 3 and Table I indicate that these devices provide significant sensor responses to trace levels of a typical VOC.

$$
\text { HH }
$$




\section{DISCLAIMER}

This report was prepared as an account of work sponsored by an agency of the United States Government. Neither the United States Government nor any agency thereof, nor any of their employees, make any warranty, express or implied, or assumes any legal liability or responsibility for the accuracy, completeness, or usefulness of any information, apparatus, product, or process disclosed, or represents that its use would not infringe privately owned rights. Reference herein to any specific commercial product, process, or service by trade name, trademark, manufacturer, or otherwise does not necessarily constitute or imply its endorsement, recommendation, or favoring by the United States Government or any agency thereof. The views and opinions of authors expressed herein do not necessarily state or reflect those of the United States Government or any agency thereof. 


\section{DISCLAIMIER}

Portions of this document may be illegible in electronic image products. Images are produced from the best available original document. 


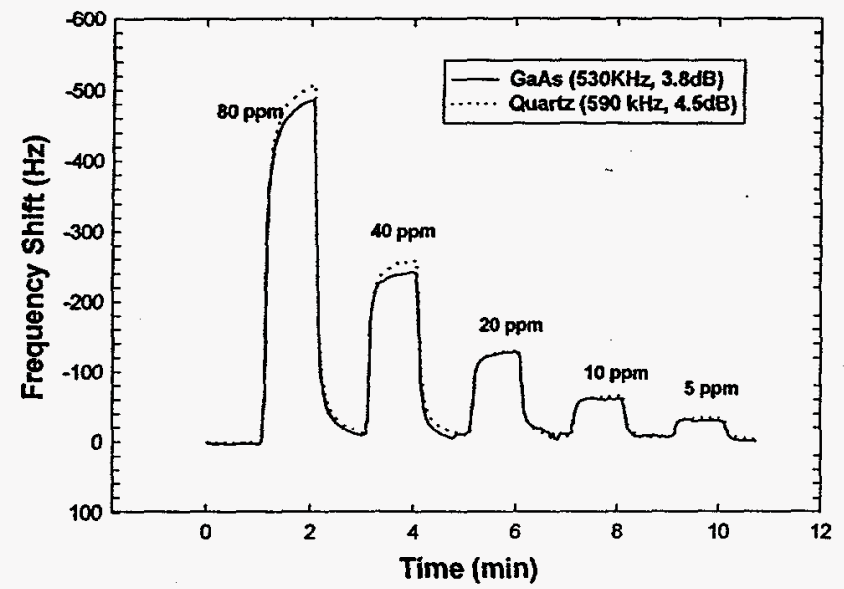

Fig. 2: Frequency responses of PIB-coated $100 \mathrm{MHz}$ GaAs and Quartz SAW devices to part per million (ppm) level step challenges of perchloroethylene (PCE). Frequency axis inverted to show positive peaks.

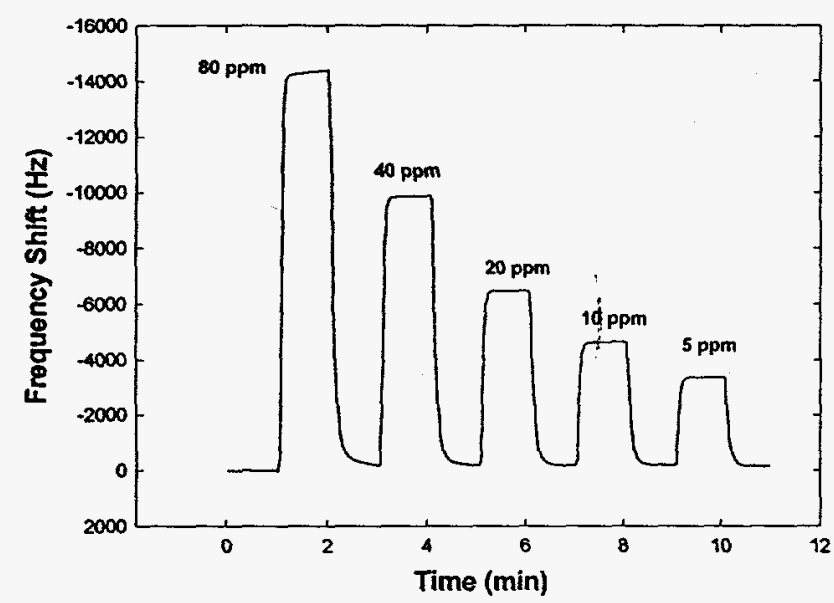

Fig. 3: Frequency shift of microporous oxide-coated $100 \mathrm{MHz}$ quartz SAW device to step challenges of PCE vapor.

A comparison of calibration coefficients for polymer-coated and microporous oxide-coated SAW devices is provided in Table $I$ along with data for an uncoated SAW device. This table shows that these microporous oxide-coated SAW devices can provide almost two orders of magnitude higher responses per ppm of PCE than polymer-coated SAW devices. In addition, the viscoelasticity of polymer coatings results in two disadvantages, high acoustic loss and increased temperature sensitivity. As shown in Table $I$, the microporous oxides, being elastic in nature, do not suffer from either of these problems. This enables thicker films to be used to further enhance sensitivity and minimizes thermally induced sensor drift (drift generally determines SAW detection levels rather than short term noise levels [2]). One difficulty with these materials is that, due to this high activity, they appear to become "clogged" by low volatility compounds. However, thermal treatments can be used to "regenerate" the material.

Table I: Comparison of poly(isobutylene) and phenylmodified microporous oxide coatings using $100 \mathrm{MHz}$ quartz $S A W S$.

\begin{tabular}{|c|c|c|c|c|}
\hline \multirow[b]{2}{*}{ Film } & \multicolumn{2}{|c|}{ Coating Induced $\Delta$} & \multirow{2}{*}{$\begin{array}{c}\text { PCE } \\
(\mathrm{Hz} / \mathrm{ppm})\end{array}$} & \multirow{2}{*}{$\begin{array}{c}\text { Temp. Co. } \\
\left(\mathrm{Hz}^{\circ} \mathrm{C}\right)\end{array}$} \\
\hline & $\mathrm{f}(\mathrm{kHz})$ & Loss $(\mathrm{dB})$ & & \\
\hline None & $\ldots$ & - & -0.11 & -350 \\
\hline \multirow[t]{2}{*}{ PIB } & 370 & 2.9 & -4.3 & -2200 \\
\hline & 1120 & 19 & -13 & -4900 \\
\hline \multirow[t]{2}{*}{ Oxide } & 200 & 2.5 & -300 & -240 \\
\hline & 340 & 2.2 & -1000 & -310 \\
\hline
\end{tabular}

For larger molecules, such as $\mathrm{CW}$ agents, films with somewhat larger micropores are required. Such films can be synthesized using a surfactant-templating process that results in films with controllable and monodisperse pore sizes (1-5 nm), high surface area $\left(1000 \mathrm{~m}^{2} / \mathrm{g}\right)$, and tailored surface chemistry [6]. Data from one such device for challenges with dimethyl methyl phosphonate (DMMP), a simulant for nerve agents such as Sarin, are shown in Figures 4 and 5.

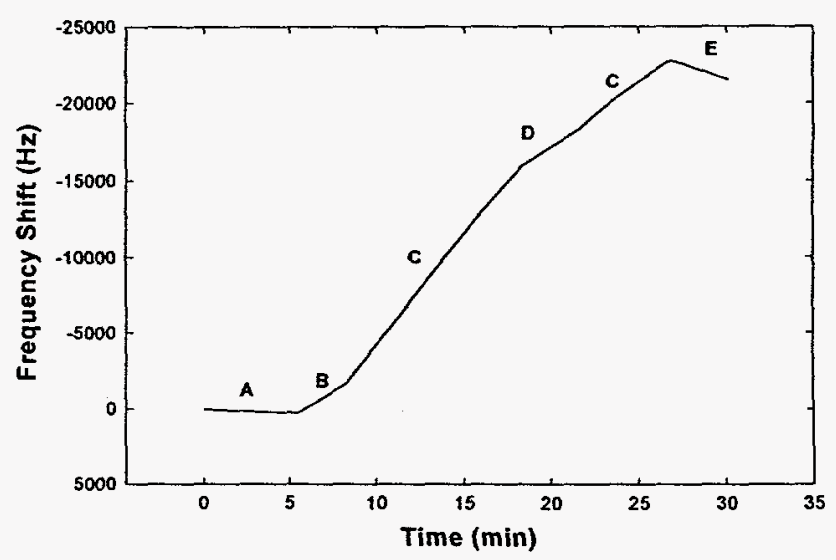

Fig. 4: Response of microporous oxide-coated $100 \mathrm{MHz}$ $S A W$ device to DMMP challenges at room temperature. A: 0 parts per billion (ppb), $20 \mathrm{~mL} / \mathrm{min}, \mathrm{B}: 220 \mathrm{ppb}, 20$ $\mathrm{mL} / \mathrm{min}, C: 220 \mathrm{ppb}, 200 \mathrm{~mL} / \mathrm{min}, \mathrm{D}: 220 \mathrm{ppb}, 40$ $\mathrm{mL} / \mathrm{min}, \mathrm{E}: 0 \mathrm{ppb}, 200 \mathrm{~mL} / \mathrm{min}$. 
At room temperature (Fig. 4), the sensor acts almost like a dosimeter effectively holding molecules that are collected. The slow response appears to be due mainly to the time required for transport of the molecules to the device surface, as seen by the increase in the rate of change when the flow rate of the gas across the sensor is increased from 20 to $200 \mathrm{~mL} / \mathrm{min}$ (B to $\mathrm{C}$ ). Removing the DMMP (E) does result in a drop in the response; however, this drop is very slow, indicating that the DMMP is not easily removed at this temperature. In contrast, at $87^{\circ} \mathrm{C} \mathrm{(Fig.} \mathrm{5),} \mathrm{the} \mathrm{sensor} \mathrm{exhibits} \mathrm{reversible}$ responses; however, response times are still not as fast as shown in Figure 3, probably due in part to mass transport limitations. These large levels of response indicate the potential for trace detection of $\mathrm{CW}$ agents using microporous-oxide coated SAW sensors.

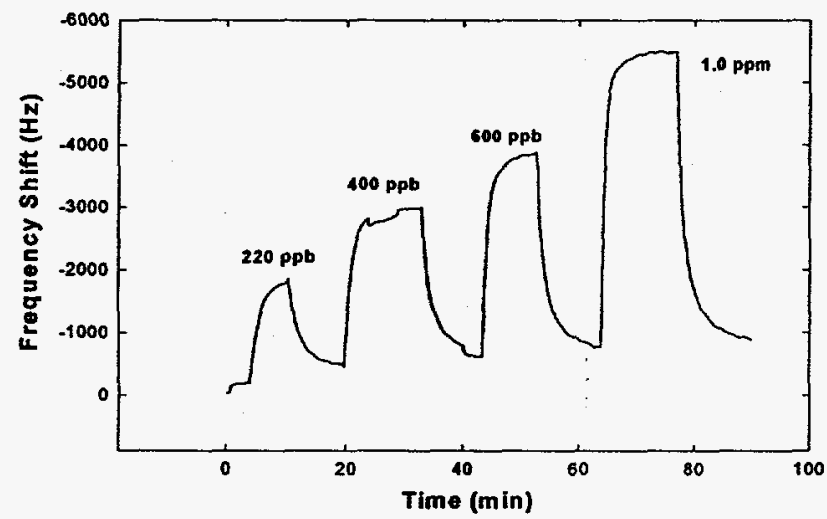

Fig. 5: Response of microporous oxide-coated $100 \mathrm{MHz}$ $S A W$ device to DMMP challenges at $87^{\circ} \mathrm{C}$. Reversible responses are observed; however, response are slow, in part due to mass transfer limitations.

\section{HIGH SENSITIVITY SAW DEVICES}

Another method of improving SAW sensor responses is to increase device operating frequency $f$. If the SAW device is used as the frequency-control element of an oscillator circuit, the magnitude of the relative frequency change ( $\Delta f / f_{o}$ where $f_{o}$ is the unperturbed SAW oscillation frequency) is the parameter of interest since noise generally increases with frequency. In this situation, the sensitivity to surface mass is given by [1]:

$$
\Delta f / f_{o}=-c_{m} f_{o} \Delta \rho_{s}
$$

where $c_{m}$ is the mass sensitivity coefficient and $\Delta \rho_{s}$ is the change in the mass/area. Increasing frequency is achieved by decreasing the periodicity of the transducers. Thus, if the relative device dimensions are maintained, the active area is proportional to $1 / f_{o}^{2}$ and the relative frequency change due to the addition of mass $(\Delta m)$ is given by:

$$
\Delta f / f_{o} \propto f_{o}^{3} \Delta m
$$

The advantage of higher frequency depends on the application. For real-time detection of ppm levels of VOCs using polymer-coated SAWs (see Fig. 2), the response is due to the equilibration of the polymer with the vapor and there is generally sufficient VOC in the vapor to equilibrate a large area. In addition, due to the viscoelastic properties, the maximum polymer film thickness that can be applied generally will decrease as $1 / f_{o}$ and, therefore, $\Delta \rho_{S}$ at a given concentration also decreases as $1 / f_{o}$. From Eq. 1 (relevant for this situation), this indicates there is no sensitivity advantage to increasing frequency, even though there is a size advantage. In contrast, for trace level detection, a significant technical challenge is collecting the very small amount of analyte and delivering it to the sensor. This makes the absolute mass sensitivity the relevant parameter and indicates that higher frequency SAWs are strongly preferred. In this case, going from 100 to 500 $\mathrm{MHz}$ will provide more than 100-fold sensitivity enhancement (see Eq. 2).

We have recently fabricated GaAs SAW devices with frequencies up to $500 \mathrm{MHz}$. The piezoelectric properties of GaAs are similar to quartz [7]. GaAs is an excellent semiconductor for high frequency electronics. In fact, monolithically integrated field-effect transistors with SAW delay lines and resonators have been developed for signal processing and frequency control applications $[8,9]$. The SAW sensors were characterized using a network analyzer. Figure 6 shows the insertion loss associated with various SAW devices overlayed with the phase shifts for the traveling acoustic wave. Nonlinearity in the phase vs. frequency can result in nonlinearities in sensor response to mass changes (oscillator circuits change frequency to maintain a constant phase). Nonlinearities can occur due to acoustic wave reflections from the transducers that traverse the acoustic path arriving with different phase from the primary wave. Gold metallization, chosen for our 
applications due to its chemical inertness, is a poor acoustic match to quartz. This is seen as readily observable ripple in the insertion loss and phase data for the quartz SAW device shown in Fig. 6a. These data are typical of the $100 \mathrm{MHz}$ quartz devices that we have been using for chemical sensor development for many years.
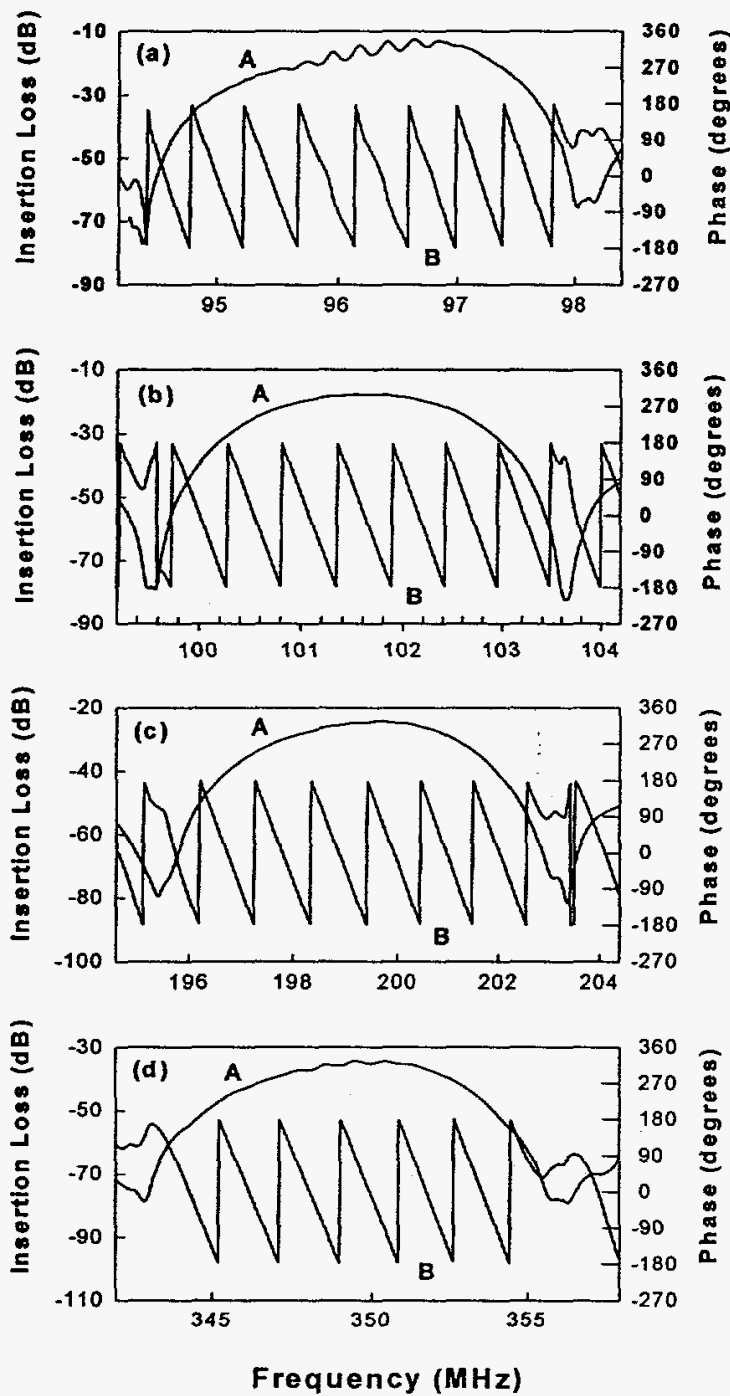

Figure 6: Insertion loss (A) and phase shift (B) as a function of frequency for ST-cut Quartz and GaAs(001)[110] SAW devices: (a) $100 \mathrm{MHz}$ Quartz, (b) $100 \mathrm{MHz}$ GaAs, (c) $200 \mathrm{MHz}$ GaAs, (d) $350 \mathrm{MHz}$ GaAs. The transmitting and receiving transducers contain 50 finger pairs each and are separated by 190 wavelengths, with a 30 wavelength acoustic beamwidth.
Figures $6 \mathrm{~b}-\mathrm{d}$ show the insertion loss and phase observed from GaAs SAW devices with three operating frequencies. Although transducer coupling coefficients are lower for GaAs transducers, typical insertion losses for GaAs SAW devices are similar to those observed on quartz. With similar matching, minimum insertion losses are about 3 to $4 \mathrm{~dB}$ higher for our $100 \mathrm{MHz}$ GaAs devices compared with $100 \mathrm{MHz}$ quartz devices (see Figs. 6a and b). Figures 6b-d also show that highly linear phase is observed for GaAs SAWs at all three frequencies. In each case, the metal thickness has been adjusted to minimize acoustic reflections from the gold transducers, yielding this high degree of linearity. As a result, GaAs SAWs are expected to provide highly linear sensing capabilities. The increase in insertion loss at higher frequencies is thought to be due to limitations in our ability to impedance match at higher frequencies using our current test fixtures. Ongoing work involves demonstrating the trace detection capabilities of these high frequency SAW devices coated with microporous oxide materials.

\section{ACKNOWLEDGMENTS}

This work was performed at Sandia National Laboratories, supported by the United States Department of Energy under Contract DE-AC04-94AL85000. Sandia is a multiprogram laboratory operated by Sandia Corporation, a Lockheed Martin Company, for the United States Department of Energy.

\section{REFERENCES}

[1] D. S. Ballantine, Jr., et al., Acoustic Wave Sensors: Theory, Design, and Physico-Chemical Applications, Academic Press, New York, 1996.

[2] G. C. Frye, et al., J. Inst. of Env. Sci. 34, 30, 1996.

[3] J. W. Grate, et al., Anal. Chem. 65, 1868, 1993.

[4] C. J. Brinker and G. W. Scherer, Sol-Gel Science, Academic Press, New York, 1990.

[5] N. K. Raman, et al., Chem. Mat., 8, 1682, 1996.

[6] R. Ganguli et al., submitted to Nature.

[7] T. Grudkowski, et al., IEEE Ultrasonics Symp. Proc., 1, 88, 1980.

[8] W. Tanski, et al., Appl. Phys. Lett., 52, 18, 1988.

[9] T. Grudkowski, et al., IEEE Trans., MTT-29, 1348, 1981. 